\title{
Mapeamento Do Uso Do Geogebra No Ensino De Estatística
}

\author{
Survey On The Use Of Geogebra In Statistical Teaching
}

\author{
Fernando Gonzales Tavares* \\ Universidade Cruzeiro do Sul (UNICSUL) \\ Celi Espasandin Lopes ${ }^{* *}$ \\ Universidade Cruzeiro do Sul (UNICSUL) \\ Universidade Cidade de São Paulo (UNICID)
}

\begin{abstract}
Resumo
Neste artigo apresenta-se um levantamento de dados obtido no banco de teses e dissertações da Coordenação de Aperfeiçoamento de Pessoal de Nível Superior (CAPES), disponíveis através de documentos de origem da Plataforma Sucupira de 2013 a 2018. Este mapeamento refere-se à produção de dissertações e teses com foco no ensino da Estatística com o uso do software GeoGebra na Educação Básica e Ensino Superior. Utilizando a palavra "Geogebra", foram encontrados 1030 registros e, após refinar a busca, usando operadores booleanos com o descritor "GeoGebra AND (Estatística OR Probabilidade)", o número diminuiu para 657 registros, dos quais somente 16 trabalhos, relacionavam, em seu resumo, a pesquisa com o ensino de Estatística ou Probabilidade. Como resultado, constatou-se existirem poucas pesquisas de mestrado e somente uma de doutorado voltada para o uso do software GeoGebra no ensino de Estatística, embora a aplicação do software no estudo de funções e geometria tenha sido foco na maioria dos 1030 trabalhos analisados.
\end{abstract}

Palavras-chave: Ensino de Estatística, Ensino Superior, Educação Básica, Software, GeoGebra.

\begin{abstract}
This paper presents a survey of data obtained from theses and dissertations database of Coordenação de Aperfeiçoamento de Pessoal de Nível Superior (CAPES), available through documents of origin of the Sucupira Platform from 2013 to 2018. This mapping refers to the production of dissertations and theses focused on the teaching of Statistics with the use of GeoGebra software in Basic Education and Higher Education. Using the word "Geogebra", 1030 records were found and, after refining the search, using Boolean operators with the descriptor GeoGebra AND (Statistics OR Probability), the number decreased to 657 records, of which only 16 papers related, in their summary, the research with the teaching of Statistics or Probability. As a result, it was verified that there are few master's researches and only one doctoral research focused on the use of GeoGebra software in Statistics teaching, although the application of software in the study of functions and geometry has been the focus of most of the 1030 papers analyzed.
\end{abstract}

Keywords: Statistics Teaching, Higher Education, Basic Education, Software, GeoGebra.

\footnotetext{
* Mestre em Engenharia Mecânica. Universidade Santa Cecília (UNISANTA). Doutorando em Ensino de Ciências e Matemática (UNICSUL), São Paulo, SP, Brasil. E-mail: gonzalez@,gonzalezft.com.

** Doutora em Educação pela Universidade Estadual de Campinas (Unicamp). Professora titular do Programa de Pós-Graduação em Ensino de Ciências e Matemática da UNICSUL, São Paulo, SP, Professora Titular do Programa de Pós-Graduação em Educação da UNICID, São Paulo, SP, Brasil. E-mail: celi.espasandin.lopes@gmail.com.
} 


\section{Introdução}

O conhecimento e o domínio dos conceitos estatísticos são importantes na formação de profissionais, por diversas e diferentes razões, mas, principalmente, para assegurar uma produção de qualidade e para uma adequada utilização de informações para a tomada de decisões nas mais diversas áreas - econômica, social, política e financeira - do País. A Lei de Diretrizes e Bases da Educação Nacional (Lei no 9.394/96) assegura que o ensino tem a finalidade de consolidar e aprofundar o conhecimento, mas também de garantir a continuidade dos estudos e a preparação para o trabalho; para o pleno exercício de cidadania, pautado na ética; e para o desenvolvimento da autonomia intelectual e a compreensão dos processos produtivos.

Artigos científicos apresentados em congressos realizados no Brasil e em outros países, tal como o IASE 2015 Satellite Conference, apontam grandes desafios para o ensino da estatística. Na última edição do Seminário Internacional de Pesquisa em Educação Matemática (SIPEM), Scarlassari e Lopes (2018) realizaram um mapeamento sobre as pesquisas brasileiras discutidas nas seis primeiras edições do SIPEM e destacaram a necessidade de que as pesquisas atuais tomem como foco de estudo o uso das tecnologias no processo de ensino e aprendizagem de estatística.

A aprendizagem estatística envolve alguns conceitos abstratos e depende de fundamentos da matemática, o que quase sempre dificulta esse processo. Um fator importante é a forma como esses conteúdos historicamente foram ensinados em sala de aula. Conforme Brignol (2004, p. 43):

O ensino tradicional da Estatística segue o modelo de aulas expositivas baseadas em apostilas ou livros clássicos no ensino da Estatística. Neste modelo, a distribuição dos conteúdos é linear e a prática na maioria das vezes é feita com exercícios e exemplos desses livros que não raro são distantes da realidade e experiência do aluno e do professor.

Atualmente o processo de ensino e aprendizagem da Estatística no Ensino Superior vem se alterando e tem incorporado práticas pedagógicas diferenciadas do ensino tradicional. A Estatística é uma disciplina do currículo de diversos cursos no Ensino Superior e, em alguns deles, sua abordagem se restringe à análise exploratória de dados; outros a ofertam como probabilidade e inferência estatística, as quais usualmente fazem parte do programa dos cursos de Engenharia de Produção, Economia, cursos da área da Saúde, entre outros. Nesses contextos, a Estatística é apresentada como parte da matemática e sua abordagem é feita a partir 
desse pressuposto. Entretanto, Lopes (2013, p. 905), alerta: "Um primeiro entendimento necessário é de que a estatística é uma ciência distinta da matemática e, portanto, seus objetos de estudo são diferenciados”. Desse ponto de vista, a Estatística “[...] fornece meios para lidar com dados que levam em conta a onipresença da variabilidade, o que a diferencia, significativamente, da matemática e outras ciências [...]”, pois considera os dados não apenas como números, mas sim como números com um contexto, no qual seus valores assumem significados diferentes.

O número 500 pode ser considerado pequeno ou grande em diferentes contextos: 500 gramas como variação na medida de peso de uma pessoa adulta não é relevante na avaliação da qualidade de vida relacionada à saúde, mas a mesma medida aplicada à avaliação de um recémnascido de alto risco é extremamente significativa.

Alguns estudantes, usuários de Estatística nos cursos de nível superior, apresentam certas dificuldades no seu aprendizado estatístico devido às lacunas relacionadas ao conhecimento matemático. Há pesquisas que apontam para as atitudes negativas com relação à matemática, para a falta de laboratórios de informática, que, aliadas à ênfase excessiva nos cálculos, são grandes obstáculos no processo de aprendizado da Estatística (Gracio \& Oliveira, 2005; Mantovani \& Viana, 2004). No entanto, o uso da tecnologia no processo de ensino e aprendizagem da Estatística pode amenizar esses obstáculos.

Na última avaliação publicada pelo Programa Internacional de Avaliação de Estudantes (PISA), realizada em 2015 e publicada pela Organização para a Cooperação do Desenvolvimento Econômico (OCDE) mais de 70\% dos alunos brasileiros entre 15 e 16 anos não alcançaram sequer o nível básico de proficiência em Matemática, isto é, são estudantes que não têm conhecimento suficiente para exercer plenamente sua cidadania (OECD, 2016). O Instituto Nacional de Estudos e Pesquisas Educacionais Anísio Teixeira (INEP), responsável pelas avaliações de ensino no País, informou em 2015 que o índice de proficiência em Matemática dos alunos do $9 .^{\circ}$ ano do Ensino Fundamental foi de $18 \%$ e dos alunos do $3 .^{\circ}$ ano do Ensino Médio, de 7\% (Parecer CNE/CP n ${ }^{\circ}$ 15/2017). Esses dados corroboram as dificuldades que nossos alunos dos cursos de graduação encontram, de uma forma geral, ao se depararem com disciplinas que exigem conhecimentos de matemática.

Em tudo há um conceito matemático. Cálculos são necessários para fazer construções e usar conceitos aprendidos na escola, porém muitos professores ensinam tão somente o conteúdo matemático, sem observar o mundo ao seu redor, a qual seria suficiente para relacionar o que está sendo ensinado, com o próprio dia a dia. 
Silva $\operatorname{Jr}(2014$, p. 21) comenta em sua tese que

no Brasil, o trabalho do professor das diferentes Ciências apresenta consequências de uma visão fragmentada e especializada de como o conhecimento científico deve ser desenvolvido. No caso das Engenharias, por exemplo, existem currículos fragmentados, nos quais não se explicitam ligações entre as diferentes áreas de conhecimento.

A abordagem dada à disciplina Estatística em cursos de nível superior é mais técnica, direcionada ao contexto do curso, causando empecilhos para os alunos estabelecerem relações amplas, dificultando sua aplicação em situações diversificadas em seu dia a dia, o que não contribui para a construção dos conceitos matemáticos e estatísticos. Para Ara (2006), um fator preponderante na dificuldade do ensino da Estatística nos cursos de engenharia é a visão equivocada da realidade, pela pouca familiaridade dos alunos com fenômenos aleatórios.

A maioria dos alunos nos cursos de engenharia é capaz de calcular limites, derivadas e integrais de forma mecânica, sem o entendimento dos conceitos matemáticos envolvidos. Tal fato fica evidente quando necessitam determinar e compreender probabilidades utilizando suas distribuições: fazem uso de tabelas estatísticas, sem perceber que esses resultados são fruto de cálculos de integrais de funções definidas por modelos estatísticos.

Segundo Carvalho e César (2000), o modo como os estudantes desenvolvem o conteúdo estatístico na sala de aula influencia o que aprendem e os seus desempenhos nessa área. Apesar de já existirem pesquisas discutindo dificuldades de aprendizagem da estatística e propondo algumas soluções, ainda se percebe a necessidade de novas investigações, pois essas dificuldades e erros podem ser devidos às metodologias e aos materiais usados, ou até mesmo a fatores até então não detectados.

Um aspecto importante no aprendizado da Estatística é que os estudantes, através da interpretação dos resultados obtidos com as análises dos dados, possam compreender os conceitos envolvidos nos problemas estudados. O uso de ferramentas tecnológicas para o tratamento dos dados pode ser um forte aliado nesse processo.

Silva e Schimiguel (2016, p. 38) entendem que

o uso de tecnologias como softwares estatísticos possibilita aos estudantes manipular conjuntos de dados maiores que aqueles apresentados na maioria dos livros utilizados como bibliografia básica ou complementar das disciplinas no Ensino Superior.

Isso tem sido possível devido à existência de uma gama de softwares estatísticos. No site da Associação Internacional de Educação Estatística (IASE), encontramos referências a ActivStats, Analyze-it, BMDP, Software Cytel, Matlab, Minitab, Palisade, R, S-Plus, SAS e a muitos outros. Ao ponderar a adoção desses softwares para atividades acadêmicas e o seu nível de usabilidade, é relevante considerar que a maioria deles foi desenvolvida com o propósito de 
"fazer" estatística e não de "aprender" estatística. Um exemplo que retrata essa situação é o software Minitab, que foi a princípio criado por três professores da Universidade Estadual da Pensilvânia em 1972, para desenvolver o ensino de Estatística com seus alunos, e hoje é utilizado em diversas organizações em todo o mundo, por empresas como Boeing, Coca-Cola, Microsoft, Walt Disney e muitas outras.

Essa diversidade de softwares contribui para atender a exigência do estudo da análise de dados, uma demanda crescente na atual sociedade. Quando essa prática se faz presente nas aulas, os estudantes podem desenvolver habilidades tecnológicas e percebem que os softwares simplificam os procedimentos estatísticos, proporcionando-lhes maior tempo do trabalho para a análise dos dados e a tomada de decisão. Assim, os estudantes podem se concentrar mais na compreensão conceitual e na construção de um pensamento estatístico, e menos na aprendizagem de um conjunto de ferramentas e procedimentos mecânicos, o que intensifica a importância de uma compreensão mais sólida dos conceitos estatísticos fundamentais.

\section{Diretrizes Para Avaliação E Instrução Em Educação Estatística}

O Guidelines for Assessment and Instruction in Statistics Education - GAISE - foi um documento publicado em 2005 pela American Statistical Association (ASA), para desenvolver diretrizes para avaliação e instrução em estatísticas no currículo K-12 (Educação Básica) e para o curso de estatística introdutório nos cursos de ensino superior americanos.

O GAISE teve um grande impacto nas instituições de ensino. As seis recomendações que compõem o documento foram revisitadas em 2016 e atualizadas (ASA, 2016). São elas:

1. Ensine o pensamento estatístico como um processo de investigação, de resolução de problemas e tomada de decisão, desenvolva no aluno a capacidade de investigar e explorar relações entre muitas variáveis.

2. Concentre-se na compreensão conceitual.

3. Trabalhe com dados reais com um contexto e propósito.

4. Promova a aprendizagem ativa.

5. Use a tecnologia para explorar conceitos e analisar dados.

6. Use avaliações para melhorar e avaliar a aprendizagem do aluno.

Neste estudo destacamos o item 5, que remete à introdução de softwares específicos para explorar conceitos e analisar dados. Ao considerar o uso da tecnologia na sala de aula, o professor deve avaliar o objetivo de aprendizagem e, em seguida, considerar quais as formas de 
tecnologia que melhor atendem a esse objetivo. No momento da escolha do software, os conhecimentos prévios em Tecnologia da Informação e da Comunicação (TIC), tanto do docente como do discente, devem ser ponderados para evitar que o seu uso se torne um fator de desmotivação para os alunos e os impeça de atingir metas ou objetivos (ASA, 2016).

Buscando na base de dados da CAPES pesquisas referentes ao uso de software estatístico, encontramos 4968 trabalhos que utilizaram os softwares: Minitab, SAS, R, SPSS, PYTHON, Matlab, SAEG, Statistics, S-Plus, GeoGebra, Bioest, entre outros. Os softwares mais empregados nas dissertações e teses foram IBM SPSS Statistics, R Project for Statistical Computing, MATLAB e GeoGebra. Existem diferentes softwares estatísticos disponíveis hoje em dia, que podem ser utilizados na organização, na análise e na interpretação de dados, mas é de fundamental importância considerar o software para ser usado na atividade acadêmica.

A tecnologia pode auxiliar os estudantes a aprender a pensar estatisticamente, permitindo que utilizem melhor o seu tempo, com o objetivo de se concentrar na interpretação de resultados através de uma aprendizagem ativa, em vez de processar informações de forma mecânica e enfadonha. Um exemplo seria o acesso a conjuntos de dados reais, os quais, na maioria das vezes, são grandes, o que torna inviável o tratamento e a análise, sem o uso de um software. Independentemente das ferramentas usadas, é essencial ver a utilização da tecnologia não unicamente como uma maneira de produzir uma solução estatística, mas como uma forma de permitir que o aluno possa investigar ideias conceituais, focar a aprendizagem da estatística sobre diferentes áreas de aplicação e, assim, perceber sua utilidade.

Concordando com essa perspectiva, o presente trabalho tem como objetivo realizar um mapeamento no banco de teses e dissertações da Coordenação de Aperfeiçoamento de Pessoal de Nível Superior (CAPES), através de documentos disponíveis na Plataforma Sucupira compreendidos entre 2013 a 2018. Esses documentos são referentes à produção de dissertações e teses, com foco sobre o uso do software GeoGebra no ensino e na aprendizagem da Estatística nos cursos de ensino fundamental, médio e superior. A opção do software Geogebra deu-se por conta de ser um dos mais utilizados entre os trabalhos pesquisados no banco de teses e dissertações da CAPES e, principalmente, por suas características de interatividade com as demais matérias de ciências exatas, o que o torna uma poderosa ferramenta no momento da aprendizagem.

\section{Geogebra Como Ferramenta Estatística}

O GeoGebra é um aplicativo interativo com os conteúdos de Geometria, Álgebra, 
Estatística e Cálculo, suas áreas de trabalho estão interconectadas e são totalmente dinâmicas. O Grupo GeoGebra é constituído pela organização sem fins lucrativos International GeoGebra Institute e GeoGebra GmbH, com sede em Linz, Áustria. Ele está disponível gratuitamente para usuários não comerciais, estudantes e professores nas plataformas Windows, MacOS e Linux, e pode ser usado em computadores de mesa, tablets e smartphones (GEOGEBRA, 2016).

O software GeoGebra, com suas janelas de visualização interativas, permite que o estudante trabalhe com mais agilidade e por isso possa buscar outros caminhos de resolução para os problemas. E, principalmente, checar se o caminho escolhido está correto. Por estar presente nos smartphones, ele é acessível e de fácil uso em qualquer ambiente com uma interface amigável e simples, feita de forma a não gerar conflitos. Essa característica é relevante, pois já se considera a ideia de que o smartphone substituirá, gradualmente, o computador. Almeida (2019), sales manager da Samsung, durante o VI Congresso Nacional da Formação Profissional, realizado no Instituto Universitário de Lisboa sob o lema "Pensar a Formação: era digital e humanismo", afirmou que até 2022 os smartphones ligar-se-ão a um monitor, lembrando que hoje isso já acontece com alguns poucos aparelhos top de linha.

No ano de 2010, o software GeoGebra foi utilizado, em uma fase do projeto de pesquisa Processo de Ensino e Aprendizagem Envolvendo Raciocínio Estatístico e Probabilístico (PEAESTAT) na construção de gráficos, potencializando sua análise estatística em razão das suas características de múltiplas janelas, e a possibilidade da construção de mais de um gráfíco em um mesmo sistema de eixos. Um dos objetivos desse projeto PEA-ESTAT era determinar quais contribuições para a formação de conceitos referentes ao Tratamento da Informação poderiam ser identificados com o uso do software GeoGebra (Coutinho, Almouloud \& Da Silva, 2012).

Os softwares estatísticos auxiliam estudantes na superação das dificuldades com operações matemáticas e minimizam a possibilidade de erro, apresentando, em segundos, os resultados para cálculos complexos. Observa-se, ao longo da atividade docente, uma defasagem entre a compreensão dos conceitos e a habilidade de cálculo da maioria dos estudantes especialmente quando a solução dos problemas estatísticos se centra na habilidade de calcular, pois se evidenciam aí certas lacunas referentes ao conhecimento matemático necessário (Tavares \& Lopes, 2017).

Em uma análise de regressão linear, usualmente o aluno desenvolve um significativo volume de cálculos, sem mesmo se aperceber do seu propósito. Com uso do GeoGebra, é possível "alimentar" a planilha de cálculo com os dados referentes às variáveis e, em seguida, plotar os pares ordenados na área de visualização gráfica, bem como apresentar os resultados 
na janela de visualização algébrica. Através das janelas de visualização do GeoGebra, é possível apresentar diversos registros do objeto matemático em estudo, proporcionando ao aluno uma visão ampla do problema e de sua solução, conforme a Figura 1.

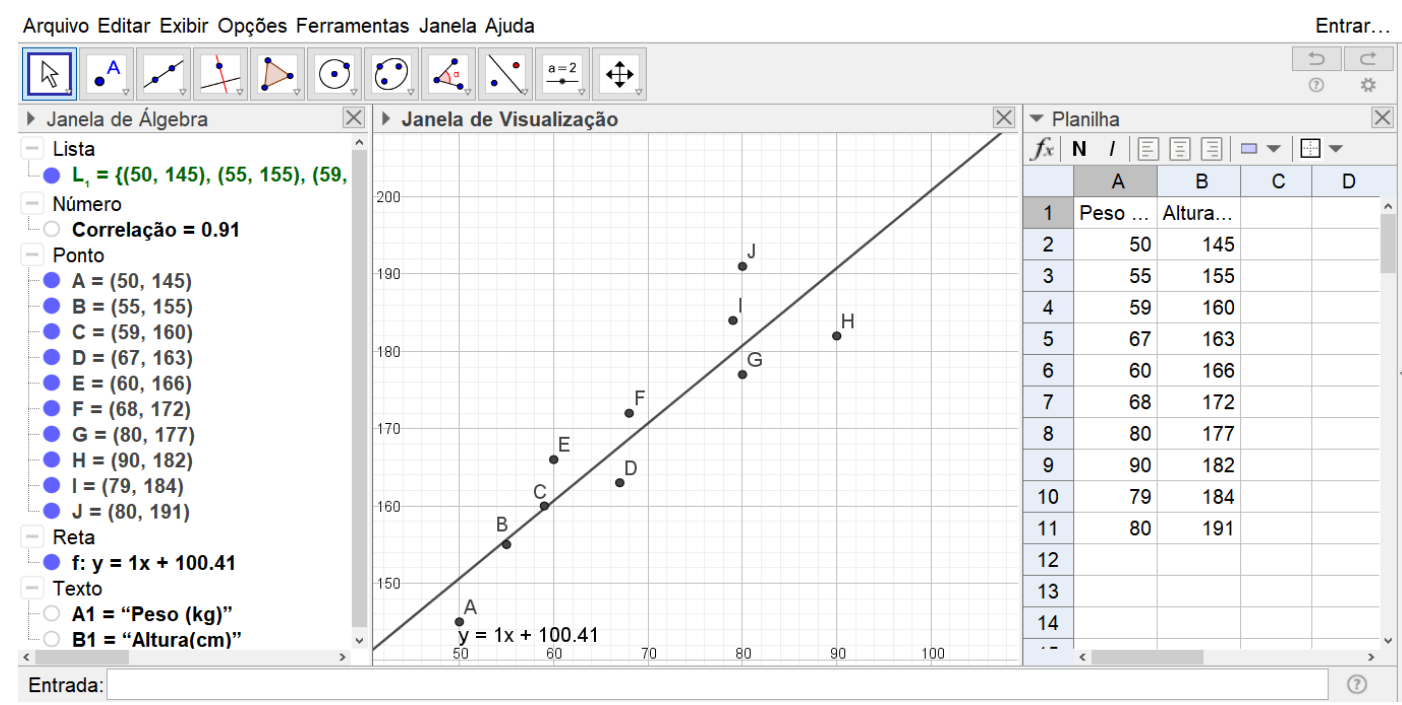

Figura 1: Representação das janelas do GeoGebra Fonte: Elaborada pelos autores

Utilizando os recursos do software GeoGebra - por exemplo, um controle deslizante-, podemos alterar qualquer valor das variáveis e construir novos conjuntos de pontos para explorar melhor a associação entre eles. Selecionando a cela B9 da planilha, criamos um controle deslizante para o seu valor na janela de visualização. Quando alteramos o valor nesse controle deslizante, o ponto $\mathrm{H}$ se desloca no plano cartesiano e, ao assumir o valor 150 , sua posição não é mais alinhada com os demais pontos, gerando mudanças significativas nos valores de correlação e no ajuste da reta de regressão linear.

\section{Metodologia E Estratégias De Ação}

O estado da arte ou estado do conhecimento é um tipo de estudo usual em outros países, mas relativamente recente no Brasil, desenvolvido inicialmente pelo Instituto Nacional de Estudos e Pesquisas Educacionais (INEP). Essas pesquisas são importantes, pois possibilitam uma visão geral do que vem sendo produzido e criam uma ordenação que permite aos interessados perceberem a evolução das pesquisas na área, bem como suas características e foco, além de identificar as lacunas ainda existentes. Conforme afirmam Romanowski e Ens (2006, pp. 38-39):

O interesse por pesquisas que abordam "estado da arte" deriva da abrangência desses estudos para apontar caminhos que vêm sendo tomados e aspectos que são abordados em detrimento de outros. A realização destes balanços possibilita contribuir com a 
organização e análise na definição de um campo, uma área, além de indicar possíveis contribuições da pesquisa para com as rupturas sociais.

Alguns pesquisadores entendem que a pesquisa denominada Estado da Arte se destina a uma coleta mais ampla, enquanto Estado do Conhecimento se restringe a um lócus mais específico de coleta de dados; essas também podem ser chamadas de mapeamento ou de pesquisas inventariantes. Um fator importante a ser considerado nesse mapeamento da produção acadêmica é que a análise somente de resumos pode ser uma limitação, pois podem ser muito confusos e até mesmo incompletos, sem informação sobre o tipo de pesquisa e os procedimentos de coleta de dados. Essas limitações dificultam e, em alguns casos, prejudicam a categorização e a análise do seu conteúdo.

Ainda sobre essa dificuldade, Ferreira (2002) comenta que a consulta aos catálogos e resumos trazem inúmeros transtornos ao pesquisador, pois muitos dos títulos de trabalhos são difusos e não revelam indicações do tema da pesquisa. Reforça a autora:

... explicável não só pelas representações diferentes que cada autor do resumo tem deste gênero discursivo, mas também por diferenças resultantes do confronto dessas representações com algumas características peculiares da situação comunicacional, como alterações no suporte material, regras das entidades responsáveis pela divulgação daquele resumo, entre outras várias. (Ferreira, 2002, p 264)

A pesquisa realizada para obtenção dos dados referentes ao trabalho é do tipo mapeamento com um caráter bibliográfico, voltada para identificar dissertações e teses produzidas no Brasil com foco em ensino de estatística no ensino fundamental, médio e superior, utilizando o software GeoGebra.

O trabalho de coleta de dados foi desenvolvido através de um levantamento realizado no banco de teses e dissertações da CAPES, consultando os registros do período de 2013 até 2018. O foco da pesquisa inicialmente foi obter a totalidade de trabalhos científicos em cujo tema constasse a palavra GeoGebra. Verificou-se a presença de 1031 registros e, após refinar a busca usando operadores booleanos com o descritor GeoGebra AND (Estatística OR Probabilidade), o número diminuiu para 658 registros. Após a leitura do tema e do resumo de cada um dos trabalhos, constatou-se que somente 15 relacionaram a pesquisa com o ensino de Estatística ou Probabilidade, porém 2 trabalhos eram idênticos. Por alguma razão técnica o sistema da base de dados da CAPES duplicou o registro da dissertação de Haroldo Costa Silva Filho, portanto o total a ser considerado de trabalhos obtidos na pesquisa foi de 1030 e com o refinamento da busca encontramos 657 registros, dos quais 14 adequaram-se ao tema ensino de Estatística ou Probabilidade com uso do software GeoGebra.

Por conta dessa discrepância observada nos registros da base de dados da CAPES e 
objetivando uma confirmação da busca inicial no banco de teses e dissertações, tornou-se a fazer uma nova pesquisa, utilizando os operadores booleanos com o descritor GeoGebra AND NOT (Estatística OR Probabilidade) e obtiveram-se 373 trabalhos, entre os quais a leitura do resumo da tese de Rodrigo Sychocki da Silva e da dissertação de Denise Ritter indicou que se enquadravam na temática estudo de probabilidades, apesar de não terem sidos classificados pelo sistema de busca da CAPES. Por essa razão, também foram lidos e analisados todos os resumos dos trabalhos da base de teses e dissertações classificados nessa segunda busca, para prevenir um eventual descarte de uma pesquisa associada ao tema do mapeamento em estudo.

A leitura dos temas de pesquisa de cada trabalho e de seus respectivos resumos resultou em 16 trabalhos, cuja pesquisa está relacionada com o uso do software GeoGebra no ensino de Estatística ou Probabilidade, conforme se observa no Quadro 1.

Quadro 1: Relação dos 16 trabalhos coletados na base de dados da CAPES

\begin{tabular}{|c|c|c|c|c|c|}
\hline Autor & Título & Ano & Instituição de ensino & $\begin{array}{l}\text { Tipo da pós- } \\
\text { graduação }\end{array}$ & Foco Temático / Nível \\
\hline $\begin{array}{l}\text { Araújo, } \\
\text { Erisvandro } \\
\text { Américo de }\end{array}$ & $\begin{array}{c}\text { Probabilidade } \\
\text { geométrica no ensino } \\
\text { médio } \text { [manuscrito]: } \\
\text { uma experiência } \\
\text { usando o Geogebra }\end{array}$ & 2017 & $\begin{array}{c}\text { Universidade } \\
\text { Estadual da Paraíba, } \\
\text { Centro de Ciências e } \\
\text { Tecnologia. } \\
\text { PROFMAT }\end{array}$ & $\begin{array}{l}\text { Mestrado } \\
\text { Profissional }\end{array}$ & $\begin{array}{l}\text { Introduzir conceitos } \\
\text { básicos de } \\
\text { Probabilidade } \\
\text { Geométrica em } \\
\text { turmas de } 2^{\circ} \text { ano do } \\
\text { Ensino Médio. }\end{array}$ \\
\hline $\begin{array}{c}\text { Barbosa, Maria } \\
\text { Beatriz } \\
\text { Guimarães }\end{array}$ & $\begin{array}{c}\text { O estudo de medidas } \\
\text { estatísticas num curso } \\
\text { de turismo: literacia, } \\
\text { raciocínio e } \\
\text { pensamento estatístico }\end{array}$ & 2012 & $\begin{array}{c}\text { Pontifícia } \\
\text { Universidade } \\
\text { Católica de Minas } \\
\text { Gerais }\end{array}$ & Mestrado & $\begin{array}{l}\text { Competências nas } \\
\text { áreas da Literacia, } \\
\text { Raciocínio e } \\
\text { Pensamento } \\
\text { Estatístico. Ensino } \\
\text { Médio. }\end{array}$ \\
\hline $\begin{array}{c}\text { Canavezi, } \\
\text { Leandro Souza }\end{array}$ & $\begin{array}{c}\text { Uma proposta lúdica } \\
\text { com utilização do } \\
\text { GeoGebra para o } \\
\text { estudo de funções } \\
\text { quadráticas e } \\
\text { probabilidade } \\
\text { geométrica }\end{array}$ & 2016 & $\begin{array}{l}\text { Universidade Federal } \\
\text { de São Carlos } \\
\text { PROFMAT }\end{array}$ & $\begin{array}{l}\text { Mestrado } \\
\text { Profissional }\end{array}$ & $\begin{array}{l}\text { Estudo de funções } \\
\text { quadráticas e } \\
\text { probabilidade } \\
\text { geométrica para } \\
\text { turmas de } 9 .^{\circ} \text { ano do } \\
\text { Ensino Fundamental. }\end{array}$ \\
\hline $\begin{array}{l}\text { Castro, Diogo } \\
\text { Meurer de } \\
\text { Souza }\end{array}$ & $\begin{array}{l}\text { Cadeias de Markov: } \\
\text { uma aplicação para o } \\
\text { ensino de matrizes e } \\
\text { probabiliodades }\end{array}$ & 2015 & $\begin{array}{c}\text { Universidade Federal } \\
\text { de Alagoas - } \\
\text { PROFMAT }\end{array}$ & $\begin{array}{l}\text { Mestrado } \\
\text { Profissional }\end{array}$ & $\begin{array}{l}\text { Trabalhar, no Ensino } \\
\text { Médio, assuntos como } \\
\text { probabilidades, } \\
\text { matrizes e sistemas } \\
\text { lineares. }\end{array}$ \\
\hline
\end{tabular}

\begin{tabular}{|c|c|c|c|c|c|}
\hline $\begin{array}{c}\text { Duarte, Lucas } \\
\text { Rodrigues }\end{array}$ & $\begin{array}{c}\text { A utilização do } \\
\text { software Geogebra no } \\
\text { ensino da distribuição } \\
\text { normal de }\end{array}$ & 2010 & $\begin{array}{c}\text { Pontifícia } \\
\text { Universidade } \\
\text { Católica de Minas } \\
\text { Gerais }\end{array}$ & Mestrado & $\begin{array}{c}\text { Trabalhar ensino e } \\
\text { aprendizagem da } \\
\text { distribuição normal de } \\
\text { probabilidade, com }\end{array}$ \\
\hline
\end{tabular}




\begin{tabular}{|c|c|c|c|c|c|}
\hline & $\begin{array}{l}\text { probabilidade: uma } \\
\text { aproximação entre a } \\
\text { geometria dinâmica e } \\
\text { a educação estatística }\end{array}$ & & & & $\begin{array}{l}\text { alunos do Curso de } \\
\text { Graduação } \\
\text { tecnológica em gestão } \\
\text { da produção } \\
\text { industrial. } \\
\end{array}$ \\
\hline $\begin{array}{l}\text { Gonçalves, } \\
\text { Paulo Henrique } \\
\text { Rodrigues }\end{array}$ & $\begin{array}{l}\text { Uma abordagem da } \\
\text { Distribuição Normal } \\
\text { através da resolução } \\
\text { de uma situação } \\
\text { problema com a } \\
\text { utilização do software } \\
\text { Geogebra }\end{array}$ & 2014 & $\begin{array}{c}\text { Universidade Federal } \\
\text { de Goiás - } \\
\text { PROFMAT }\end{array}$ & $\begin{array}{l}\text { Mestrado } \\
\text { Profissional }\end{array}$ & $\begin{array}{l}\text { Desenvolver uma } \\
\text { abordagem da } \\
\text { Distribuição Normal } \\
\text { através da resolução } \\
\text { de uma situação } \\
\text { problema com uma } \\
\text { turma de terceiro ano } \\
\text { do Ensino Médio. }\end{array}$ \\
\hline $\begin{array}{l}\text { Leite, Rafael } \\
\text { Ferreira da } \\
\text { Costa }\end{array}$ & $\begin{array}{c}\text { A utilização de } \\
\text { tecnologia para } \\
\text { estatística no ensino } \\
\text { médio: uma proposta } \\
\text { de aula com o suporte } \\
\text { doGoogle Docs e do } \\
\text { Geogebra }\end{array}$ & 2017 & $\begin{array}{l}\text { Universidade Federal } \\
\text { do Estado do Rio de } \\
\text { Janeiro. PROFMAT }\end{array}$ & $\begin{array}{l}\text { Mestrado } \\
\text { Profissional }\end{array}$ & $\begin{array}{l}\text { Foco do estudo em } \\
\text { estatística com } \\
\text { aplicações para alunos } \\
\text { do Ensino Médio }\end{array}$ \\
\hline $\begin{array}{l}\text { Medeiros, } \\
\text { Sérgio da Silva }\end{array}$ & $\begin{array}{c}\text { Cadeias de Markov } \\
\text { ocultas }\end{array}$ & 2017 & $\begin{array}{l}\text { Universidade Federal } \\
\text { do ABC. PROFMAT }\end{array}$ & $\begin{array}{l}\text { Mestrado } \\
\text { Profissional }\end{array}$ & $\begin{array}{l}\text { Estudo das Cadeias de } \\
\text { Markov e das Cadeias } \\
\text { de Markov Ocultas. } \\
\text { Ensino Médio. }\end{array}$ \\
\hline $\begin{array}{l}\text { Nascimento, } \\
\text { Leandro } \\
\text { Mendonça do }\end{array}$ & $\begin{array}{c}\text { A utilização de } \\
\text { tecnologia para } \\
\text { estatística no Ensino } \\
\text { Fundamental II: Uma } \\
\text { proposta de aula com } \\
\text { o suporte do Google } \\
\text { Docs e do GeoGebra }\end{array}$ & 2017 & $\begin{array}{l}\text { Universidade Federal } \\
\text { do Estado do Rio de } \\
\text { Janeiro. PROFMAT }\end{array}$ & $\begin{array}{l}\text { Mestrado } \\
\text { Profissional }\end{array}$ & $\begin{array}{c}\text { Foco do estudo em } \\
\text { estatística com } \\
\text { aplicações para alunos } \\
\text { do Ensino } \\
\text { Fundamental. }\end{array}$ \\
\hline Ritter, Denise & $\begin{array}{c}\text { O ensino de } \\
\text { Probabilidade } \\
\text { Geométrica: desafios } \\
\text { e possibilidades }\end{array}$ & 2017 & $\begin{array}{c}\text { Centro Universitário } \\
\text { Franciscano }\end{array}$ & Mestrado & $\begin{array}{c}\text { Probabilidade } \\
\text { Geométrica na } \\
\text { aprendizagem do } \\
\text { conceito de } \\
\text { Probabilidade com } \\
\text { estudantes do segundo } \\
\text { ano do Ensino Médio. }\end{array}$ \\
\hline $\begin{array}{l}\text { Rocha, Samy } \\
\text { Marques }\end{array}$ & $\begin{array}{c}\text { Distribuição binomial } \\
\text { e aplicações }\end{array}$ & 2017 & $\begin{array}{c}\text { Universidade Federal } \\
\text { do Maranhão. } \\
\text { PROFMAT }\end{array}$ & $\begin{array}{l}\text { Mestrado } \\
\text { Profissional }\end{array}$ & $\begin{array}{l}\text { Construção do modelo } \\
\text { binomial e suas } \\
\text { principais } \\
\text { características para os } \\
\text { alunos do Ensino } \\
\text { Médio. }\end{array}$ \\
\hline
\end{tabular}




\begin{tabular}{|c|c|c|c|c|c|}
\hline $\begin{array}{l}\text { Santos, Elaine } \\
\text { Costa dos }\end{array}$ & $\begin{array}{l}\text { Proposta de aplicação } \\
\text { da Estatística no } \\
\text { ensino da Matemática } \\
\text { na Educação Básica: } \\
\text { uma Investigação do } \\
\text { cotidiano com o } \\
\text { auxílio do Geogebra }\end{array}$ & 2013 & $\begin{array}{l}\text { Universidade Federal } \\
\text { da Bahia. PROFMAT }\end{array}$ & $\begin{array}{l}\text { Mestrado } \\
\text { Profissional }\end{array}$ & $\begin{array}{l}\text { Proposta de ensino da } \\
\text { Matemática na } \\
\text { Educação Básica } \\
\text { utilizando o conteúdo } \\
\text { matemático referente } \\
\text { à Estatística para } \\
\text { alunos do Ensino } \\
\text { Médio }\end{array}$ \\
\hline $\begin{array}{l}\text { Silva Filho, } \\
\text { Haroldo Costa }\end{array}$ & $\begin{array}{l}\text { Probabilidade e valor } \\
\text { esperado discussão de } \\
\text { problemas para o } \\
\text { ensino médio }\end{array}$ & 2016 & $\begin{array}{c}\text { Pontifícia } \\
\text { Universidade } \\
\text { Católica do Rio de } \\
\text { Janeiro }\end{array}$ & Mestrado & $\begin{array}{c}\text { Desenvolver a noção } \\
\text { de valor esperado de } \\
\text { uma variável aleatória } \\
\text { no Ensino Médio. }\end{array}$ \\
\hline $\begin{array}{c}\text { Silva, Andreia } \\
\text { Aparecida Costa }\end{array}$ & $\begin{array}{c}\text { Aproximação da } \\
\text { distribuição binomial } \\
\text { pela distribuição } \\
\text { normal: uma } \\
\text { abordagem no ensino } \\
\text { de distribuição normal } \\
\text { de probabilidade }\end{array}$ & 2015 & $\begin{array}{l}\text { Universidade Federal } \\
\text { de São João Del-Rei. } \\
\text { PROFMAT }\end{array}$ & $\begin{array}{l}\text { Mestrado } \\
\text { Profissional }\end{array}$ & $\begin{array}{l}\text { Trabalhar com o } \\
\text { professor do Ensino } \\
\text { Médio na } \\
\text { comprovação de } \\
\text { alguns resultados } \\
\text { teóricos e } \\
\text { características da } \\
\text { curva normal por } \\
\text { meio de ensaios } \\
\text { investigativos. }\end{array}$ \\
\hline $\begin{array}{c}\text { Silva, Carlos } \\
\text { Vinícius Ramos } \\
\text { da }\end{array}$ & $\begin{array}{c}\text { Estatística no } 9^{\circ} \text { ano } \\
\text { de ensino } \\
\text { fundamental: Uma } \\
\text { abordagem } \\
\text { contextualizada e } \\
\text { interdisciplinar }\end{array}$ & 2018 & $\begin{array}{l}\text { Universidade Federal } \\
\text { da Bahia PROFMAT }\end{array}$ & $\begin{array}{l}\text { Mestrado } \\
\text { Profissional }\end{array}$ & $\begin{array}{c}\text { O foco da pesquisa é o } \\
\text { ensino da Estatística } \\
\text { no nono ano do } \\
\text { Ensino Fundamental } \\
\text { de forma } \\
\text { contextualizada, } \\
\text { interdisciplinar e com } \\
\text { auxílio de software } \\
\text { GeoGebra }\end{array}$ \\
\hline $\begin{array}{l}\text { Silva, Rodrigo } \\
\text { Sychocki da }\end{array}$ & $\begin{array}{l}\text { Cadeias de Markov e } \\
\text { modelagem } \\
\text { matemática: da } \\
\text { abstração pseudo- } \\
\text { empírica à abstração } \\
\text { refletida com uso de } \\
\text { objetos virtuais }\end{array}$ & 2015 & $\begin{array}{l}\text { Universidade Federal } \\
\text { do Rio Grande do Sul }\end{array}$ & Doutorado & $\begin{array}{c}\text { Apresentar as } \\
\text { contribuições da } \\
\text { informática na } \\
\text { construção de } \\
\text { conceitos matemáticos } \\
\text { para estudantes do } \\
\text { ensino médio, } \\
\text { superior e professores } \\
\text { de Matemática. }\end{array}$ \\
\hline
\end{tabular}

Fonte: Elaborado pelos autores

\section{Resultados E Discussão}

Após a realização de uma primeira classificação dos trabalhos para identificar o ano de sua publicação, foram encontrados dois trabalhos anteriores à plataforma Sucupira, as dissertações de Maria Beatriz Guimarães e Lucas Rodrigues Duarte, os quais não davam acesso 
ao seu resumo e tampouco ao trabalho. Estes foram pesquisados nas bases de dados das respectivas instituições de ensino, onde foi possível ter acesso aos trabalhos na sua íntegra, os quais, após suas análises, foram relacionados, com fundo cinza, na Tabela 1.

Inicialmente foi utilizado como fonte básica de referência no levantamento dos dados o banco de teses e dissertações da CAPES, porém, em razão de não existir catálogo de detalhamento de algumas dessas publicações, se fez necessário buscar maiores informações nas bases de dados das respectivas universidades, referentes a trabalhos publicados em anos anteriores a 2013. Os dados fornecidos continham os títulos das dissertações de mestrado e teses de doutorado, a indicação do autor e do orientador, os resumos, as palavras-chave e o ano de defesa do trabalho. A leitura dos resumos nem sempre permite a identificação da metodologia utilizada na abordagem do problema de pesquisa, pois alguns deles são sucintos e nem sempre informam com clareza o objetivo principal da investigação.

Os trabalhos foram analisados utilizando os relatórios de detalhamento da CAPES em um primeiro momento, mas notou-se que, para a organização do material, seria preciso não só a leitura dos títulos dos estudos e seus catálogos, mas, principalmente, a leitura dos resumos originais de cada pesquisa. Em muitos casos se fez necessário também uma leitura direcionada do trabalho completo, na busca de subsídios para determinar a metodologia de pesquisa empregada e sua fundamentação teórica, em razão de nem sempre ter sido possível encontrar essas informações e outros aspectos relevantes somente por meio dos resumos.

Nas modalidades dos cursos de pós-graduação stricto sensu, mestrados e doutorados, foram encontrados nove dissertações de Mestrado Profissional e quatro de Mestrado Acadêmico e uma tese de Doutorado versando sobre o uso do software GeoGebra no ensino e na aprendizagem de Estatística ou Probabilidade.

Tabela 1: Número de trabalhos por ano de publicação

\begin{tabular}{ccc}
\hline Ano & Freq. Absoluta & Freq. Relativa \\
\hline 2010 & 1 & $6,25 \%$ \\
2012 & 1 & $6,25 \%$ \\
2013 & 1 & $6,25 \%$ \\
2014 & 1 & $6,25 \%$ \\
2015 & 3 & $18,75 \%$ \\
2016 & 2 & $12,50 \%$ \\
2017 & 6 & $37,50 \%$ \\
2018 & 1 & $6,25 \%$ \\
Total & 16 & $100,00 \%$ \\
\hline
\end{tabular}

Fonte: Elaborada pelos autores

A leitura e a análise do Quadro1 proporcionaram uma melhor organização e síntese dos dados em novas tabelas, especificando e quantificando as variáveis em estudo e suas categorias. 
A Tabela 1 apresenta a distribuição dos trabalhos entre os anos de 2010 e 2018 e chama a atenção à quase total ausência de publicações no período compreendido entre os anos de 2010 e 2014 e o aumento significativo de trabalhos apresentados no ano de 2017, representando $37,5 \%$ do total das pesquisas.

Observa-se, nesse período anterior ao ano de 2017, a ocorrência de eventos que podem ter influenciado e acentuado o interesse na pesquisa com a utilização de softwares na área de exatas, mas especificamente no ensino e na aprendizagem de estatística. Como por exemplo, no ano de 2015, a prova do Programa Internacional de Avaliação de Estudantes (PISA) aplicada integralmente com computador e avaliação focada em leitura, matemática e ciências. No mesmo ano ocorreu a Conferência Satélite IASE 2015, organizada pela Associação Internacional de Educação Estatística (IASE) e pela Universidade Federal do Estado do Rio de Janeiro (UNIRIO). Ainda citando eventos importantes, a publicação, em 2016, do relatório Guidelines for Assessment and Instruction in Statistics Education (GAISE), o qual, sem dúvida, foi um fator considerado impactante no aumento, no ano de 2017, das defesas de dissertações e teses envolvendo o uso de softwares no ensino e na aprendizagem de estatística.

Tabela 2: Foco dos níveis de ensino abordados nos trabalhos entre 2010-2018

\begin{tabular}{ccc}
\hline Nível de Ensino & Freq. Absoluta & Freq. Relativa \\
\hline Ensino Fundamental & 2 & $12,50 \%$ \\
Ensino Médio & 12 & $75,00 \%$ \\
Ensino Superior & 2 & $12,50 \%$ \\
Total & 16 & $100,00 \%$ \\
\hline
\end{tabular}

Fonte: Elaborada pelos autores

Observando a Tabela 2, concluímos que 75\% das dissertações e teses foram desenvolvidas com base em pesquisas voltadas ao Ensino Médio, porém nessa categoria foram encontrados cinco trabalhos cujos temas se reportam a Distribuição Normal, Distribuição Binomial e Cadeias de Markov. O nível de dificuldade para o seu entendimento é significativo, pois requer um conhecimento prévio de álgebra linear, de teoria das probabilidades e conceito de variáveis aleatórias. Apesar de os autores dessas pesquisas terem considerado trabalhar com essas temáticas no nível de Ensino Médio, após a leitura dos trabalhos, por conta da complexidade dos assuntos, que envolviam a abordagem de cálculo de integrais, logaritmos hiperbólicos, binômios de Newton, teorema de Bayes e relação entre modelos de distribuição de probabilidades, considerou-se que seria adequado enquadrá-los na categoria de Ensino Superior.

Tabela 3: Dissertações e teses, defendidas nas Instituições de Ensino Superior Instituições de Ensino Freq. Absoluta Freq. Relativa 


\begin{tabular}{ccc} 
Universidade Estadual da Paraíba & 1 & $6,25 \%$ \\
Pontifícia Universidade Católica de Minas Gerais & 2 & $12,50 \%$ \\
Universidade Federal de São Carlos & 1 & $6,25 \%$ \\
Universidade Federal de Alagoas & 1 & $6,25 \%$ \\
Universidade Federal de Goiás & 1 & $6,25 \%$ \\
Universidade Federal do Estado do Rio de Janeiro & 2 & $12,50 \%$ \\
Universidade Federal do ABC & 1 & $6,25 \%$ \\
Centro Universitário Franciscano & 1 & $6,25 \%$ \\
Universidade Federal do Maranhão & 1 & $6,25 \%$ \\
Universidade Federal da Bahia & 2 & $12,50 \%$ \\
Pontifícia Universidade Católica do Rio de Janeiro & 1 & $6,25 \%$ \\
Universidade Federal de São João Del-Rei & 1 & $6,25 \%$ \\
Universidade Federal do Rio Grande do Sul & 1 & $6,25 \%$ \\
Total & 16 & $100,00 \%$ \\
\hline
\end{tabular}

Fonte: Elaborada pelos autores

$\mathrm{Na}$ Tabela 3, foram ranqueadas as Instituições de Ensino com base no número de trabalhos existentes no catálogo de teses e dissertações da CAPES, no período compreendido entre os anos de 2010 e 2018. Treze instituições de ensino no Brasil contribuíram para a construção de pesquisas voltadas ao ensino e aprendizagem de Estatística com o uso do software GeoGebra, resultando em uma distribuição quase uniforme em relação ao total de 16 trabalhos. É importante ressaltar que 12 dissertações são oriundas do curso semipresencial Mestrado Profissional em Matemática em Rede Nacional (PROFMAT), realizado por uma rede de Instituições de Ensino Superior no contexto da Universidade Aberta do Brasil, coordenado pela Sociedade Brasileira de Matemática (SBM).

Tabela 4: Foco dos temas abordados nos trabalhos entre 2010-2018

\begin{tabular}{ccc}
\hline Foco Temático & Freq. Absoluta & Freq. Relativa \\
\hline Estatística descritiva & 5 & $31,25 \%$ \\
Probabilidade & 5 & $31,25 \%$ \\
Distribuição Binomial & 1 & $6,25 \%$ \\
Cadeias de Markov & 2 & $12,50 \%$ \\
Distribuição Normal & 3 & $18,75 \%$ \\
Total & 16 & $100,00 \%$ \\
\hline
\end{tabular}

Fonte: Elaborada pelos autores

Foi realizada uma leitura do título das dissertações e teses e de seus resumos, buscando identificar inicialmente o seu foco temático, principalmente para o estabelecimento de categorias da tipologia dos temas, como revela a Tabela 4, e foram agrupados em cinco categorias.

As pesquisas cujo conteúdo versa sobre estatística descritiva e probabilidade representam $62,5 \%$ dos focos temáticos; no entanto, o percentual de trabalhos desenvolvidos no Ensino Médio e no Ensino Fundamental representa $87,5 \%$ dos focos nos níveis de ensino. 
Essa discrepância nos percentuais indica que existem trabalhos classificados pelos autores cujos temas tratam de conceitos de Distribuição Normal, Binomial e Cadeias de Markov, sendo abordados como conteúdo no Ensino Médio e em etapas anteriores.

Tabela 5: Metodologia de Pesquisa abordada nos trabalhos entre 2010-2018

\begin{tabular}{ccc}
\hline Metodologia & Freq. Absoluta & Freq. Relativa \\
\hline Estudo de Caso & 5 & $31,25 \%$ \\
Engenharia Didática & 5 & $31,25 \%$ \\
Observação Participante & 1 & $6,25 \%$ \\
Revisão Bibliográfica & 4 & $25,00 \%$ \\
Abordagem dos Três Momentos Pedagógicos & 1 & $6,25 \%$ \\
Total & 16 & $100,00 \%$ \\
\hline
\end{tabular}

Fonte: Elaborada pelos autores

Uma característica importante no mapeamento foi a escolha da metodologia adotada nas pesquisas. Todas usam de uma abordagem qualitativa, sendo que a Engenharia Didática, na perspectiva de Michèle Artigue, foi adotada em grande parte dos trabalhos num total 33,25\% bem como estudo de caso também com 33,25\% dos trabalhos analisados. As sequências didáticas foram utilizadas como instrumento de coleta e análise dos dados das investigações desenvolvidas nos trabalhos. A revisão bibliográfica foi outra metodologia de pesquisa bem utilizada representando $25 \%$ do total elencado, como exibe a Tabela 5 .

\section{Considerações Finais}

Apesar de ser a Estatística cada vez mais utilizada, dada a sua importância na formação científica e ética de cidadãos e ao seu crescente uso em uma sociedade informatizada, em resultados de pesquisas nas mais diversas áreas do conhecimento, na busca realizada na base de teses da Coordenação de Aperfeiçoamento de Pessoal de Nível Superior (CAPES), encontramos poucas pesquisas em nível de dissertações e teses voltadas para o uso do software GeoGebra no ensino de Estatística.

No mapeamento feito no banco dados da CAPES, foram encontrados somente 16 trabalhos com temas relacionados com conteúdo de Estatística ou Probabilidade, representando apenas $1,6 \%$ das pesquisas desenvolvidas com o software GeoGebra no período entre 2010 a 2018. Nos últimos quatro anos houve uma concentração dessas pesquisas: foram defendidas 11 dissertações e uma tese. Um fato importante observado é que 9 dessas dissertações são provenientes do Programa de Mestrado Profissional - PROFMAT.

Importante salientar que o inventário realizado no catálogo de teses e dissertações da Capes apresentou limitações, pois muitos dos títulos de trabalhos são difusos, não revelam 
indicações do tema da pesquisa e vários de seus resumos não apresentam de forma clara os objetivos do trabalho, nem indicam a metodologia da pesquisa e sua fundamentação teórica. A leitura dos trabalhos na íntegra foi necessária para suprir a falta dessas informações.

Evidenciou-se na pesquisa uma lacuna: a pouca produção de trabalhos voltados para o Ensino Superior, apenas 12,5\%, um abordando o tema Cadeias de Markov e Modelagem Matemática e outro, Distribuição Normal de probabilidades. Esses temas também foram tratados em pesquisas focadas no Ensino Médio, porém sem a profundidade e a aplicação que poderiam ter recebido em um curso de graduação.

Outra lacuna é a ausência, nos trabalhos analisados, de um maior aprofundamento no uso do software, com a discussão de conceitos e a simulação de situações que permitissem levantar conjecturas e testar hipóteses. Pouco foi explorada a sua característica de interatividade com suas múltiplas plataformas, que reúnem Geometria, Álgebra, janela de visualização gráfica em 2D e 3D, Planilha, Estatística, Probabilidade, Cálculo Diferencial e Integral. É possível discutir o valor da probabilidade de uma distribuição em um determinado intervalo e apresentar seus resultados na janela de visualização gráfica, utilizando a planilha de cálculo. Observou-se, na leitura dos trabalhos, o uso do software GeoGebra no desenvolvimento dos temas abordados, de forma quase semelhante a uma calculadora gráfica, como, por exemplo, usando seus comandos apenas para calcular o valor de médias e desvios padrões, sem, no entanto, discutir a variabilidade dos dados envolvidos. Com o uso do controle deslizante na janela de visualização, é possível criar cenários diferentes e propiciar a discussão sobre a homogeneidade dos dados, a consequente ausência de outliers e até a validade da média como medida representante da amostra na presença de variabilidade significativa dos dados.

Com a utilização do recurso tecnológico - o software GeoGebra -, os pesquisadores desenvolveram diversas atividades, principalmente voltadas ao Ensino Médio e Superior, na aprendizagem e no ensino da Estatística e da Probabilidade. Mas efetivamente só dois trabalhos desenvolveram satisfatoriamente a aplicação do software. Os critérios utilizados para avaliação do adequado aproveitamento do software no ensino de estatística foram: inovação na forma de apresentar os conceitos estatísticos, aproveitando os recursos computacionais de interação do GeoGebra com a álgebra e a geometria plana; utilização de dados reais presentes nos contextos de vidas dos estudantes, sem a preocupação de reduzir o tamanho das amostras, por conta da dificuldade ao computar os cálculos envolvidos; gerar simulações de novos contextos com alterações nos valores dos dados, criando situações propícias para discussões dos conceitos estatísticos estudados. Especificamente, buscamos atender à quinta recomendação do relatório 
GAISE, avaliando o quanto o uso do software GeoGebra propiciou a compreensão do comportamento dos dados e a exploração de conceitos estatísticos abordados nos trabalhos analisados. Essa é uma avaliação fruto da nossa leitura do inventário pesquisado, sujeita às limitações de nossas percepções e de nossa compreensão sobre o tema.

Consideramos que, dada a relevância da Estatística não só para o aprendizado como também para seu uso, que embasa a tomada de decisões nos mais variados campos da ciência e sociedade como um todo, se faz necessário buscar trabalhos em outras formas de divulgação, além das teses e dissertações, pois é pouco provável que não tenham ocorrido outras pesquisas voltadas ao estudo do ensino da Estatística com o uso de softwares GeoGebra.

Ademais, com a utilização do descritor "Software AND (Estatística OR Probabilidade)" na pesquisa preliminar, foram encontrados 4968 registros que incluíram diversos softwares, dos quais os mais citados, além do GeoGebra, foram IBM SPSS Statistics, o R Project for Statistical Computing e o MATLAB, com, respectivamente, 536, 252 e 223 trabalhos. Esses dados indicam a possibilidade e a necessidade de novos mapeamentos na avaliação do uso específico de outros softwares no ensino e na aprendizagem de Estatística e Probabilidade.

\section{Referências}

Almeida, N. (2019, abril). Pensar a formação: Era digital, humanismo e aprendizagem ao longo da vida. In Anais do 6 Congresso Nacional da Formação Profissional. Lisboa, Portugal: Instituto Universitário de Lisboa. Recuperado de https://www.forma-te.com/cnfp2019.php

Ara, A. B. (2006). O ensino de Estatística e a busca do equilíbrio entre os aspectos determinísticos e aleatórios da realidade. Tese de Doutorado, Faculdade de Educação, Universidade de São Paulo, São Paulo.

ASA (2016). College Report Revision Committee. Guidelines for Assessment and Instruction in Statistics Education College Report (GAISE). Recuperado de http://www.amstat.org/education/gaise

Brignol, S. M. S. (2004). Novas tecnologias de informação e comunicação nas relações de aprendizagem da Estatística no Ensino Médio. Monografia Especialização em Educação Estatística, Faculdades Jorge Amado, Salvador.

Carvalho, C., \& César, M. (2000). As aparências iludem: reflexões em torno de ensino da estatística no ensino básico. Lisboa: Sociedade Portuguesa de Estatística, Faculdade de Ciências da Universidade de Lisboa.

Coutinho, C. Q. S., Almouloud, S., \& Da Silva, M. J. F. (2012). O desenvolvimento do letramento estatístico a partir do uso do Geogebra: um estudo com professores de matemática. Revemat: Revista Eletrônica de Educação Matemática. doi: https://doi.org/10.5007/1981-1322.2012v7n2p246 
Ferreira, N. S. de A. (2002) As pesquisas denominadas "estado da arte". Educação \& Sociedade, 23(79), 257-272.

GEOGEBRA. (2016). What is GeoGebra? In: Putting the world's leading dynamic mathematics software and materials in the hands of students and teachers everywhere. Recuperado de https://www.geogebra.org/about

Gracio, M. C. C., \& Oliveira, E. F. T. (2005) O ensino de Estatística na UNESP/Campus de Marília. Educação Matemática em Revista, 17, 9-15.

IASE (2019). International Association for Statistical Education. Software. Recuperado de https://iase-web.org/Links.php?p=Software

Lei $n^{\circ}$ 9.394, de 1996. (1996). Lei de Diretrizes e Bases para a Educação Nacional. Brasília: MEC. Recuperado de http://www.presidencia.gov.br/ccivil_03/Leis/L9394.htm

Lopes, C. E. (2013). Educação Estatística no Curso de Licenciatura em Matemática. Bolema, 27(47), 901-915.

Mantovani, D. M. N., \& Viana, A. B. N. (2004). Ensino de Estatística para cursos de graduação em Administração de Empresas: novas perspectivas. In Anais 7 Seminário de Administração FEA-USP. Recuperado de http://sistema.semead.com.br/7semead/

OECD (2016). PISA 2015 Assessment and analytical framework: Science, reading, mathematic and financial literacy. OECD Publishing. Recuperado de http://dx.doi.org/10.1787/9789264255425-en

Parecer $C N E / C P n^{o} 15 / 2017$ (2017). Portaria $n^{\circ} 1570$, publicada no D.O.U. de 21/12/2017, Seção 1, p. 146. Base Nacional Curricular. Brasília: CNE/MEC. Recuperado de http://portal.mec.gov.br/index.php?option=com_docman\&view $=$ download\&alias $=78631$ pcp015-17-pdf\&category_slug=dezembro-2017-pdf\&Itemid=30192

Romanowski, J. P., \& Ens, R. T. (2006). As pesquisas denominadas do tipo "estado da arte" em Educação. Diálogo Educ., 6(19), 37-50.

Scarlassari, N. T., \& Lopes, C. E. (2018, novembro). Mapeamento dos trabalhos publicados no GT12 do SIPEM. Anais do 7 Seminário Internacional de Pesquisa em Educação Matemática. Recuperado de http://www.sbemparana.com.br/viisipem/

Silva, J. F., \& Schimiguel, J. (2016). Problem-based learning, Educação Estatística e Educação a Distância: um estudo teórico sobre possíveis convergências no ensino superior. Revista de Ensino de Ciências e Matemática, 7(3), 38.

Silva JR, G. B. (2014). O ensino de Estatística na Formação inicial do engenheiro de produção. Tese de Doutorado em Ensino de Ciências e Matemática, Universidade Cruzeiro do Sul, São Paulo.

Tavares, F. G., \& Lopes, C. E. (2017, julho). Estudo da viabilidade de uso do software GeoGebra no ensino de Estatística. In Anais Congresso Iberoamericano de Educación Matemática (pp.14-22). Madrid, España. Recuperado de http://www.cibem.org/images/site/LibroActasCIBEM/ComunicacionesLibroActas_CB40 1-500.pdf 
ISSN 1981-1322

Recebido em: 02/04/2019

Aceito em: 07/09/2019 